\title{
Integration of climate change considerations into local air quality management plans in South Africa
}

\author{
Tirusha Thambiran ${ }^{1,2}$, Roseanne Diab $^{2}$ and Mark Zunckel ${ }^{1 *}$ \\ 1. CSIR Natural Resources and the Environment, P O Box 17001, Congella, 4103, South Africa \\ 2. School of Environmental Sciences, University of KwaZulu-Natal, Howard College Campus, Durban 4041, \\ South Africa \\ * uMoya-Nilu, 23 Ashley Avenue, Glen Ashley, Durban, 4051, South Africa
}

\section{Introduction}

Due to the synergistic and antagonistic relationships that exist in the environmental policy arena, environmental policies cannot be treated in isolation (Hayes, 2006). The concept of integrated environmental management serves as a useful activity to enhance the ability to manage a resource that is affected by anthropogenic activities (Pahl-Wostl, 2007). Integrated environmental management allows for a broad perspective to be taken, whereby all the possible trade-offs and benefits are considered at various spatial and temporal scales (PahlWostl, 2007). The atmospheric composition of the earth is greatly impacted on by anthropogenic emissions that lead to a variety of environmental management concerns.

The combustion of fossil fuels (coal, oil and gas) and biomass for use as energy in homes, industries and motor vehicles, leads to a wide spectrum of air emissions that include nitrogen oxides (NOx), volatile organic compounds (VOCs), sulphur dioxide $\left(\mathrm{SO}_{2}\right)$, nitrogen dioxide $\left(\mathrm{NO}_{2}\right)$, methane $\left(\mathrm{CH}_{4}\right)$, carbon dioxide $\left(\mathrm{CO}_{2}\right)$, and particulate matter (PM). These emissions result in a variety of atmospheric issues that threaten the status of human health and ecosystems through problems such as acidification, eutrophication, anthropogenic induced climate change and smog. Traditionally when it comes to dealing with these problems, policies and scientific research have developed in isolation from each other.

Air quality (AQ) research for example, has primarily focused on traditional air pollutants namely $\mathrm{SO}_{2}, \mathrm{PM}, \mathrm{NO}_{2}$, ozone $\left(\mathrm{O}_{3}\right)$, $\mathrm{CO}$, whereas climate change (CC) research has focused on the science of the greenhouse gases (GHGs) namely, $\mathrm{CO}_{2}$, nitrous oxide $\left(\mathrm{N}_{2} \mathrm{O}\right), \mathrm{CH}_{4}$, hydrofluorocarbons (HFCs), perfluorocarbons (PFCs) sulphur hexafluoride $\left(\mathrm{SF}_{6}\right)$, and $\mathrm{O}_{3}$ responsible for the internal radiative forcing of the climate. Furthermore, the policies to deal with these issues have also developed at different scales. Policy to deal with air pollution is generally developed at a national level, with opportunities for regional and local policies, where the ultimate goal is the protection of health and ecosystems through air quality management (AQM). CC policy has, however, developed at an international level, with the aim to mitigate $\mathrm{CC}$ through a reduction of GHGs and to adapt to the consequent damage that could occur. The dominant international policy for CC mitigation is the Kyoto Protocol which requires countries that have ratified it, to report on GHG emissions (non-annex 1 countries) or achieve certain reductions of GHG emissions by specified time periods (annex 1 countries).

$\mathrm{AQ}$ and $\mathrm{CC}$ are two issues that are primarily driven by the same action, which is the combustion of fossil fuels. Therefore it would seem that there would be synergies to integrated management of $\mathrm{AQ}$ and $\mathrm{CC}$ concerns. Separate policies and research in isolation have resulted in the cobenefits of an integrated policy that simultaneously considers both issues being overlooked (Alcamo et al., 2002; Swart et al., 2004). As such we find that there was a gap in knowledge on the scientific understanding between the links between $\mathrm{CC}$ and AQ. The Intergovernmental Panel on Climate Change (IPCC) in its third assessment report in 2001 acknowledged the need to investigate the linkages between CC and AQ and as consequence of this, in the last decade there has been an emerging priority for environmental policy to develop an improved understanding of the linkages and interactions between CC and AQ. The recently published IPCC fourth assessment report has documented some of the linkages between CC and AQ (Denman et al., 2007). Furthermore, cities in many of the developed nations such as the United Kingdom and the United States of America (USA) which have established AQM programmes are in the process of trying to capture the synergies between AQM and $\mathrm{CC}$ mitigation.

Integration of $\mathrm{AQ}$ and $\mathrm{CC}$ policies could ultimately occur in one of two ways. The first method of integration could be achieved by considering AQ improvements as a result of CC mitigation measures, where the reduction of traditional air pollutants is seen as an ancillary benefit to GHG mitigation. It has been documented that such ancillary benefits of GHG mitigation are more likely to be an attractive incentive for those countries with Kyoto Protocol obligations to reduce their GHG emissions (Krupnick et al., 2002). However, in developing countries, the ancillary benefit of CC mitigation measures that is, reduced air pollution, is more likely to be the primary objective of air pollution related policy.

Alternatively, $\mathrm{CC}$ considerations can be integrated into AQM. Research does indicate that integrating $\mathrm{CC}$ considerations into AQM strategies could be advantageous in developing countries. More 
specifically, it is recognised that there are significant benefits associated with the integration of AQ and $\mathrm{CC}$ at a local level. Research shows that municipalities have the potential to make a significant contribution to international efforts to curb CC as half of the world's population lives in urban areas (Bestill, 2001). This has resulted in the old saying of 'think global and act local' to be seen as being insufficient and a new strategy to 'think locally and act locally' is instead promoted (Bestill, 2001). This highlights the need to frame CC within a local context in order to promote local action. An integrated policy at a local level would allow for the maximization of the synergistic relationship between the two issues and the avoidance of overlaps in policies such that there is reduction of mitigation costs and more effective monitoring. Further, at a local level, GHG reductions can be achieved alongside policies designed to improve the liveability of communities, where reduced air pollution yields short to medium term benefits and $\mathrm{CC}$ benefits are long-term. Thus, there are significant incentives for developing countries to consider the CC impacts of their local policies.

\section{The South African Context}

In South Africa, there is a high dependency on combustion of coal for electricity use, where the generation of electricity from coal is the largest emitter of GHGs in the country (Mukheibir, 2007). Furthermore, the total estimated anthropogenic GHG emissions in 2000 were 365 MTonne C02eq (mainly $\mathrm{CO}_{2}$ ) and contributed about $1.6 \%$ of the total world carbon equivalent emissions (Hong $e t$ al, 2002).

Electricity generation from coal is also a significant contributor to air pollution in South Africa. However, air pollutant sources also stem from the industrial sector which is the largest energy consumer in South Africa, and the transportation sector which is dominated by passenger transport, carbon intensive fuels and increased motorized vehicles for public transport. Furthermore, due to poverty and the economics of the country indoor air pollution is a major problem in the country, as fossil fuels are burnt indoors for cooking and heating.

South Africa has a constitutional obligation to provide its citizens with an environment that is not armful to their health or well-being and furthermore, has a global responsibly to act against $\mathrm{CC}$. The South African government acceded to the Kyoto Protocol in July 2002 and is a non-annex 1 country and is therefore only required to report on GHG emissions at this time. AQ has received much attention in South Africa in recent years due to the promulgation of the National Environmental Management: Air Quality Act (AQA, Act 39 of 2004 ) in September 2005. The AQA is widely regarded as being 'world class' air pollution legislation. However, by dealing with the issues of $\mathrm{CC}$ and $\mathrm{AQ}$ in isolation at a policy level, South
Africa is overlooking the co-benefits of an integrative policy. At this stage of developing the country's response to $C C$ and the further development of AQ legislation, South Africa is perfectly poised to capitalize on an opportunity to find the most cost effective way of simultaneously dealing with these issues. Furthermore, it is important to note that even though other countries have recognised the need for integrated policies, often they have fallen short on maximizing the synergies of $C C$ and $A Q$. For example, the new Canadian AQ legislation is criticized as just providing lip service' to integration of the issues. Even though their AQ legislation does discuss ah pollutants and GHGs, the mitigation and control of the pollutants are handled separately and the synergistic relationship between the two issues is not considered (Williams and Chiotti, 2006). Thus, if South Africa is able to develop more holistic AQ legislation that incorporates CC considerations, it will not only set an example for the rest of Africa but will also be a global pioneer in this field.

As it is recognized that integrating $\mathrm{CC}$ considerations into local AQM plans (AQMPs) has the potential to be beneficial in developing countries, this is the method of integration that is pursued in this study. More specifically, a mechanism that will facilitate the integration of these issues at local level in South Africa is through the AQA which requires that each municipality must include an AQMPS in its integrated development plan (IDP) as required in terms of Chapter 5 of the Municipal Systems Act, where AQM focuses on finding the most cost effective air improvement strategy.

The eThekwini Municipality has been progressive in its approach in dealing with AQ issues, with the inception of an extensive AQ monitoring network and the development of its draft AQMP. The eThekwini Municipality has also undertaken investigations into CC in terms of key challenges, potential impacts and responses required by the municipality, and is in the process of developing an integrated assessment model for determining the mitigation and adaptation measures for various sectors of the municipality that will affected by CC (Hounsome, 2007). The eThekwini Municipality therefore, represents an ideal case study to investigate integrating CC considerations into local AQMPs in South Africa.

\section{Scientific linkages between $\mathrm{CC}$ and $\mathrm{AQ}$}

There are numerous factors that need to be taken into account regarding $\mathrm{CC}$ and $\mathrm{AQ}$. AQ and $\mathrm{CC}$ are linked by virtue of the fact that they are driven by the combustion of fossil fuels. However GHGs and air pollutants may directly and indirectly impact on each other. Furthermore, CC is anticipated to affect sources of air pollutants as well as impact on the ability of pollutants to be dispersed in the atmosphere. These topics are discussed further in the subsequent sections highlighting the scientific 
basis for integrating policies regarding atmospheric emissions.

\subsubsection{Tropospheric $\mathrm{O}_{3}$}

Tropospheric $\mathrm{O}_{3}$ is formed as a secondary pollutant and affects the self cleansing ability of the atmosphere (Jacob, 1999; Oltmans et al, 2006). It is also harmful to health and ecosystems, and is often a priority for AQM (Bernard et al, 2001; Dentener etal., 2006).

Tropospheric $\mathrm{O}_{3}$ is also GHG with the third largest radiative forcing (Forster et al, 2007), the concentrations of which have increased since preindustrial times (Shindell et al, 2006). In addition to this, the precursor gases of $\mathrm{O}_{3}$ that are treated as traditional air pollutants also have an indirect effect on the climate, as they affect the lifetime of other gases. A prime example is the impact that $\mathrm{NO}_{\mathrm{x}}$ and $\mathrm{CO}$ have on $\mathrm{CH}_{4}$.

\subsubsection{Aerosols}

Aerosols are fine particles that are suspended in the air, the sources of which may be both natural and anthropogenic (Andreae and Crutzen, 1997). Natural sources provide the primary aerosol particles and anthropogenic sources include $\mathrm{SO}_{2}$ and $\mathrm{NH}_{3}$ responsible for secondary aerosol particles. Aerosols or particulate matter have serious implications for health leading to respiratory illnesses (Bernard et al., 2001).

Aerosols also are a $\mathrm{CC}$ problem. Aerosols affect the climate both directly and indirectly. Sulphate aerosols contribute to cooling the earth by reflecting sunlight back into space and preventing it from reaching the earth's surface (Andreae et al, 2005; Kaufmann et al., 1991). The total amount of sulphate aerosols is estimated to be about 10 times larger than the total amount of black carbon (BC) aerosols which contribute to warming the atmosphere (Jacobson, 2002). Aerosols also affect the climate indirectly though changes to clouds. Aerosols act as cloud condensation nuclei (CCN) and thus added aerosols alter the cloud-drop size distribution (Andreae, 2007; Hudson, 1992). Thus increases in aerosols yields smaller cloud drops and thus larger cloud albedo. This is often referred to as the "cloud albedo effect" where the decreased droplet size and increased droplet number results in increased reflectivity (Mitchells and Johns, 1997). It is suggested that reduction of aerosols for AQM purposes could be unfavourable for global warming.

\subsection{3 $\mathrm{SO}_{2}$}

$\mathrm{SO}_{2}$ is a major focus of AQM due to the associated health effects as once inhaled it results in a variety of acute and chronic illnesses (Matooane and Diab, 2003).

Sulphur emissions are also related to acidification, and contribute to the formation of the sulphate aerosol which has a cooling effect on the climate
(Mayehofer et al., 2002;Posch et al., 1996) which means that $\mathrm{AQ}$ management of $\mathrm{SO}_{2}$ might reduce both the direct and indirect cooling effects that the sulphate aerosol produces.

\subsection{4 $\mathrm{CH}_{4}$}

$\mathrm{CH}_{4}$ is a GHG and has the second largest radiative forcing and is the shortest-lived with of the GHGs with a lifetime of about 7.9 yrs (Lelieveld et al, 1998). Atmospheric concentrations of $\mathrm{CH}_{4}$ levels have increased since the $19^{\text {th }}$ century due to rapid agricultural expansion and industrialization (Lelieveld et al, 1998). One added $\mathrm{CH}_{4}$ molecule absorbs infra-red radiation is about 25 times more efficiently than an added $\mathrm{CO}_{2}$ molecule. However, $\mathrm{CO}_{2}$ is seen as a priority in $\mathrm{GHG}$ mitigation as $\mathrm{CO}_{2}$ levels are 200 times higher, so that many of its absorption lines are already saturated (Lelieveld et al, 1998; Wuebbles and Hayhoe, 2002).

$\mathrm{CH}_{4}$ is a precursor gas to the formation of background $\mathrm{O}_{3}$ with evidence of strong coupling between $\mathrm{CH}_{4}$ increases and $\mathrm{O}_{3}$ levels. The reduction of $\mathrm{CH}_{4}$ emissions is seen as being a "triple dividend" as it will have many benefits for mitigating $\mathrm{CC}$ and improving $\mathrm{AQ}$, as in addition to the initial decrease in radiative forcing from $\mathrm{CH} 4$, there will be subsequent reductions in harmful $\mathrm{O}_{3}$ concentrations and a reduction of $\mathrm{O}_{3}$ radiative forcing. (West and Fiore, 2005).

\subsubsection{NO $\mathrm{N}_{\mathrm{x}}$ and VOCs}

$\mathrm{NO}_{\mathrm{x}}$ and VOCs have multiple effects as they are the limiting agents in the photochemical production of $\mathrm{O}_{3}$ and also contribute to $\mathrm{NO}_{2}$ (which contributes to the problem of eutrophication) and PM concentrations, having an indirect effect on human health.

Furthermore, $\mathrm{NO}_{\mathrm{x}}$ and VOCs also influence the rate of $\mathrm{CH}_{4}$ destruction. $\mathrm{NO}_{\mathrm{x}}$ emissions, for example, generate indirect radiative forcing by shortening the lifetime of $\mathrm{CH}_{4}$ through the enhancement of the $\mathrm{OH}$ radical.

\subsubsection{Summary of major pollutants and their multiple effects}

From the above discussion it is clear that atmospheric emissions result in multiple pollutants that have numerous effects on health and the environment. Table 1 provides a summary of these pollutants and their multiple effects.

\subsection{Impact of $\mathrm{CC}$ on air pollutants}

CC can have a significant impact on the chemical composition of the atmosphere. Atmospheric transport processes (wind, convection, stratospheric-tropospheric exchange $\{\mathrm{STE}\})$, 
Table 1: Summary of the pollutant and their multiple effects (Adapted from Amann, 2007)

\begin{tabular}{|c|c|c|c|c|c|c|c|c|}
\hline Acidification & $\mathrm{SO}_{2}$ & $\mathbf{N O}_{\mathrm{x}}$ & & VOCs & $\mathrm{CO}$ & $\begin{array}{l}\text { Primary } \\
\text { Particles }\end{array}$ & $\mathrm{CH}_{4}$ & $\mathrm{CO}_{2}$ \\
\hline Eutrophication & & $\mathbf{V}$ & $\mathbf{V}$ & & & & & \\
\hline $\begin{array}{l}\text { Ground-level } \\
\text { ozone } \\
\text { Health } \\
\text { impacts via } \\
\text { sec.aerosols }\end{array}$ & V & & V & & $\begin{array}{l}\mathbf{V} \\
\mathbf{V}\end{array}$ & $\mathbf{V}$ & V & \\
\hline $\begin{array}{l}\text { Radiative } \\
\text { forcing } \\
\text { Direct } \\
\text { Via aerosols } \\
\text { Via OH }\end{array}$ & V & V & V & $\begin{array}{l}\mathbf{V} \\
\mathbf{V}\end{array}$ & V & V & $\begin{array}{l}\mathbf{V} \\
\mathbf{V}\end{array}$ & $\mathbf{V}$ \\
\hline
\end{tabular}


transformation controls (temperature, relative humidity, removal processes, precipitation), emission controls (effects natural and anthropogenic emissions) could all be affected by CC (Forster et $a l, 2007)$. There is significant research that has been carried out on the effects of $\mathrm{CC}$ on tropospheric $\mathrm{O}_{3}$ and is discussed in more detail here.

Changes in atmospheric circulation could impact on tropospheric $\mathrm{O}_{3}$, as STE should increase because of the stronger Brewer-Dobson stratospheric circulation. Convection is expected to intensify as the climate warms, though this might not be the case in the tropics. It is expected that natural and anthropogenic sources of the precursor gases of $\mathrm{O}_{3}$ will change; this will include NOx emissions from soils and lightning; biogenic VOC emissions from vegetation and an increase in energy demands (Bell and Ellis, 2004; Brasseur et al., 2006; Forster et al., 2007). Changes in temperature, humidity and UV radiation will also impact on $\mathrm{O}_{3}$ production (Grewe, 2007). Model results show that surface $\mathrm{O}_{3}$ concentrations will increase due to chemical production as a consequence of CC (Racherla and Adams, 2007).

\subsection{CC impact on the occurrence of air pollution events}

$\mathrm{CC}$ results in progressive changes to weather patterns that include changes to the distribution and amount of precipitation, to temperature, wind speed, wind direction and large-scale weather producing systems (Meehll et al., 2000). These factors all contribute to atmospheric stability and are key factors responsible for the dispersion of pollutants. These changes will therefore have an impact on the occurrence and severity of air pollution events. Model predictions for the US show an increased severity and duration of summertime regional pollution episodes in parts of USA (Lueng and
Gustafon, 2005; Mickley et al., 2004; Prather et al, 2003, Tao et al., 2007).

\section{4 . Integrated assessment tools for $A Q$ and $C C$}

Atmospheric emissions from processes are generally controlled in one of three ways which are (Boubel et al., 1994):

- Changes to processes which lead to less pollution or reduced emissions (eg. through a change in operations).

- Change in fuel

- End-of-pipe technology

These measures are generally implemented with respect to air pollution control or CC mitigation without consideration of each other. However, there are control measures that directly or indirectly affect both CC and AQ pollutants. There are numerous technologies that reduce both air pollutants and GHGs, for instance engine technologies which reduce $\mathrm{CO}_{2}$ emissions also result in Tower NOx emissions. However, there are numerous instances where a control measure targeted at a particular pollutant, might result in increased emissions of other pollutants. For example, desulphurization using $\mathrm{Ca} \mathrm{CO}_{3}$ results in decreased sulphur emissions but also results in an increase in $\mathrm{CO}_{2}$ emissions (EEA,2004).

Furthermore, it is generally accepted that end-ofpipe technologies that are selected for AQM can lead to limited emissions reduction before control options that require more extreme measures becomes necessary. This may for example require a change in fuel, from fossil fuels to renewable energy, which is the focus of CC mitigation (to reduce $\mathrm{CO}_{2}$ emissions by using cleaner sources of energy). Thus, AQM and CC mitigation are inextricably linked requiring long-term integrative 
policies. The intention of this project is by no means a mechanism to detract from the need to reduce $\mathrm{CO}_{2}$ emissions through energy measures but should allow municipalities to moderate $\mathrm{GHG}$ emissions through the control of traditional air pollutants, alongside measures that specifically act to reduce GHGs. Thus there is a need to identify an integrated assessment tool that will allow for the estimation of GHG emissions generated as a result of different control options for traditional air pollutants. There are numerous models or software that are available for dealing with control options for AQ and CC. However, there are far fewer models available that simultaneously address both issues.

Of the tools available, two have been identified as being appropriate for the scope of this project. The first of these tools was developed by the International Institute for Applied Systems Analysis (IIASA). Initially IIASA had developed the Regional Air Pollution Information and Simulation (RAINS) model which served as a tool to assess emission control strategies for traditional air pollutants $\left(\mathrm{SO}_{2}, \mathrm{NO}_{\mathrm{x}}, \mathrm{VOCs}, \mathrm{NH}_{3}\right.$ and $\left.\mathrm{PM}\right)$, addressing health impacts, acidification and eutrophication. The RAINS model has been extended to include GHGs $\left(\mathrm{CO}_{2}, \mathrm{CH}_{4}, \mathrm{~N}_{2} \mathrm{O}, \mathrm{CFC}\right.$, $\mathrm{HFC}, \mathrm{SF}_{6}$ ) in the Greenhouse gas-Air pollution Interactions and Synergies (GAINS) model which captures the interactions between the control of traditional air pollutants and GHGs (Amann, 2007a). GAINS allows for the selection of the emission control measure that is cost-effective for more than one pollutant simultaneously. These emission control measures include behavioural changes, structural measures such as fuel substitution, and technical measures that contain approximately 1500 end-of-pipe technologies for reducing traditional air pollutants, 500 measures which have an impact on more than one pollutant (Amann, 2007a). South Africa became a member of IIASA on 1 July 2007 as part of a Department of Science and Technology (DST) and the National Research Foundation (NRF) initiative to promote collaboration with IIASA and South African researchers.

The second tool is the Clean Air Climate Protection Software (CACP) software that was developed by International Council for local Environmental Initiatives (ICLEI) as part of their Cities for Climate Protection (CCP) programme. The CACP software was specifically designed for the creation of emissions scenarios for use in the planning process or the creation of full emissions reduction plans. Specifically it allows for the tracking of emissions and reductions of the GHGs $\left(\mathrm{CO}_{2}, \mathrm{~N}_{2} \mathrm{O}\right.$, and $\left.\mathrm{CH}_{4}\right)$ and traditional air pollutants $\left(\mathrm{SO}_{2}, \mathrm{NO}_{\mathrm{x}}, \mathrm{VOC}\right.$ and PMIо) that are related to electricity, fuel use and waste disposal. The CACP software consists of thousands of emission coefficients for all of the major GHGs and air pollutants for a variety of technologies, fuels and electricity options (CACPS, 2007). Thus, the software is able to quantify the reduction of GHGs and air pollutants from a range of control options Local authorities are thus able to use the software to quantify existing and proposed emission reduction measures so they are able to compare alternative emission reduction strategies. Numerous South African cities are members of the ICLEI and CCP programme, which includes the eThekwini Municipality. The ICLEI provides its members with resources, technical assistance and software tools. The eThekwini Municipality Greenhouse Gas Emissions Surveys in 2002 and 2004 were developed as part of the CCP programme.

These tools mentioned above, have been used widely in Europe (GAINS) and the USA (CACP). However, these tools have predominantly been used to show the ancillary benefits of improved AQ as a result of GHG mitigation measures. For example the use of the GAINS model in Europe showed that fuel strategies to reduce $\mathrm{CO}_{2}$ emissions (by 15\%) would result in a simultaneous decrease in air pollutants $\left(\mathrm{SO}_{2}\right.$ by $25 \%$ and $\mathrm{NO}_{\mathrm{x}}$ by $\left.8 \%\right)$, such that the improvements to AQ would prevent thousands of premature deaths (Amann, 2004b). CACP software has been used extensively in the USA to analyze the impacts $\mathrm{GHG}$ emission reduction plans on air pollutant emissions (Fig.1).

However, these tools have also been designed, and thus have the ability to allow for the selection of control strategies that address the reduction of traditional air pollutants and ancillary GHG benefits. Thus, both options (GAINS and CACP) will have to be further investigated in order to evaluate which option will be most suitable and viable for use in South Africa to assess the ancillary benefits of AQM.

\section{Case Study: eThekwini Municipality}

As mentioned earlier, for the purposes of this project, the eThekwini Municipality has been selected as a case study. This case study will entail conducting an impact analysis of the proposed AQMP for the eThekwini Municipality, focusing on AQ and CC issues. The draft AQMP has thus far, prioritized areas for intervention, that include, $\mathrm{SO}_{2}$, рміо, flaring from refineries, odours, benzene, indoor AQ and the problem area of Jacobs (eThekwini Municipality, 2007). As part of the AQM action plan, the municipality suggests control strategies to reduce emissions of traditional air pollutants from each of the priority areas. The intention is to investigate the impact that the control measures identified in the AQM action plan will have on GHG emissions. A further objective is, to find alternative control measures that allow the municipality to best capture the synergistic relationship between traditional air pollutants and GHGs in order to have an AQM action plan in place that reduces emissions of traditional air pollutants, whilst simultaneously reducing the municipality's contribution of GHG emissions. A suitable integrated assessment tool (such as the GAINS model or CACP software) will be adapted for use 
Community Measures

Transportation Measures

Expand Mass Transit Bus

System

Increased Use of

Alternative Fuels in Motor

Vehicles

Land Use Planning

Decrease motor vehicle
Emission Reductions for each Measure (tons)

-Note: negative numbers indicate increases in emissions

No. So. vOC CO
$-8.521$

$\underline{1,904}$

Figure 1: CACP Software analysis for transportation control measures in climate action plan of Durham, USA (Yienger et al. 2007).

in the municipality and be used to create different emission scenarios to identify the control strategies that result in the most economically viable options for $\mathrm{AQ}$ and $\mathrm{GHG}$ emission reductions.

\section{Expected outcomes}

Reducing air pollutants produces short to medium term benefits for health and ecosystems. However, the goal of integrating CC considerations into AQM plans is to have measures in place that do not contribute to GHG emissions or ideally measures that reduce GHG emissions. This project will provide the basis for understanding the linkages that exist between $\mathrm{AQ}$ and $\mathrm{CC}$ and provide the impetus towards long-term integrative $\mathrm{AC}$ and $C C$ policies. As municipalities in South Africa begin to develop CC action plans, to specifically control GHG sources, these plans will also have to be analyzed so as to determine the optimal control strategies that harvest the ancillary benefits of reduced air pollutants.

This project, therefore, forms an integral part of the first phase towards developing an integrated Air Quality and Climate Change Action Plan for municipalities in South Africa (Fig. 2), the analysis of potential CC action plans would also take place in phase 1 . Phases 2 and 3 of such a plan would require commitment from various stakeholders (different spheres of government, community groups, industries ana researchers) within the municipality to ensure effective implementation and compliance to obtain the most holistic control on atmospheric emissions (Fig.2).

The advantages of an integrated AQ and CC action plan is that an optimal approach for simultaneously reducing traditional air pollutants and GHGs will be developed, which will result in the improvement of quality of life of South Africans, who will encounter the short-term benefits of reduced air pollutants and which will contribute to the longterm reduction of GHGs.

\section{Acknowledgements}

The authors are grateful to the CSIR and the International Start Secretariat for financial support.

\section{References;}

Alcamo, J., Mayerhofer, P., Guardians, R., van Harmelen, T., van Minnen, J., Onigkeit, J., Posch, M. and de Vries, B. (2002). An integrated assessment of regional air pollution and climate change in Europe: findings of the AIR-CLIM Project. Environmental Science \& Policy, 5, 257-272.

Amann, M. (2004a). GAINS - Greenhouse Gas and Air Pollution Interactions and Synergies. Available at: http:// www.iiasa.ac.at/gains/model\%20description.htmI. Date accessed 13 April, 2007.

Amann, M. (2004b). Synergies between GHG Mitigation and Air Pollution Control. UNFCCC Conference of the Parties 10. Available at: http://www.iiasa.ac.at/rains/reports/ COP10.pdf. Date accessed: 21 June, 2007.

Amann, M. (2007). Pollution control over scales: from local health impacts to global climate. IIASA Symposium in South Africa. April 11-13, 2007. Pretoria, South Africa.

Andreae, M. O., Jones, CD. and Cox, P.M. (2005). Strong present-day aerosol cooling implies a hot future. Nature. 435(30), doi: 10.1038/nature03671.

Andreae, M.O. (2007). Atmospheric aerosols versus 


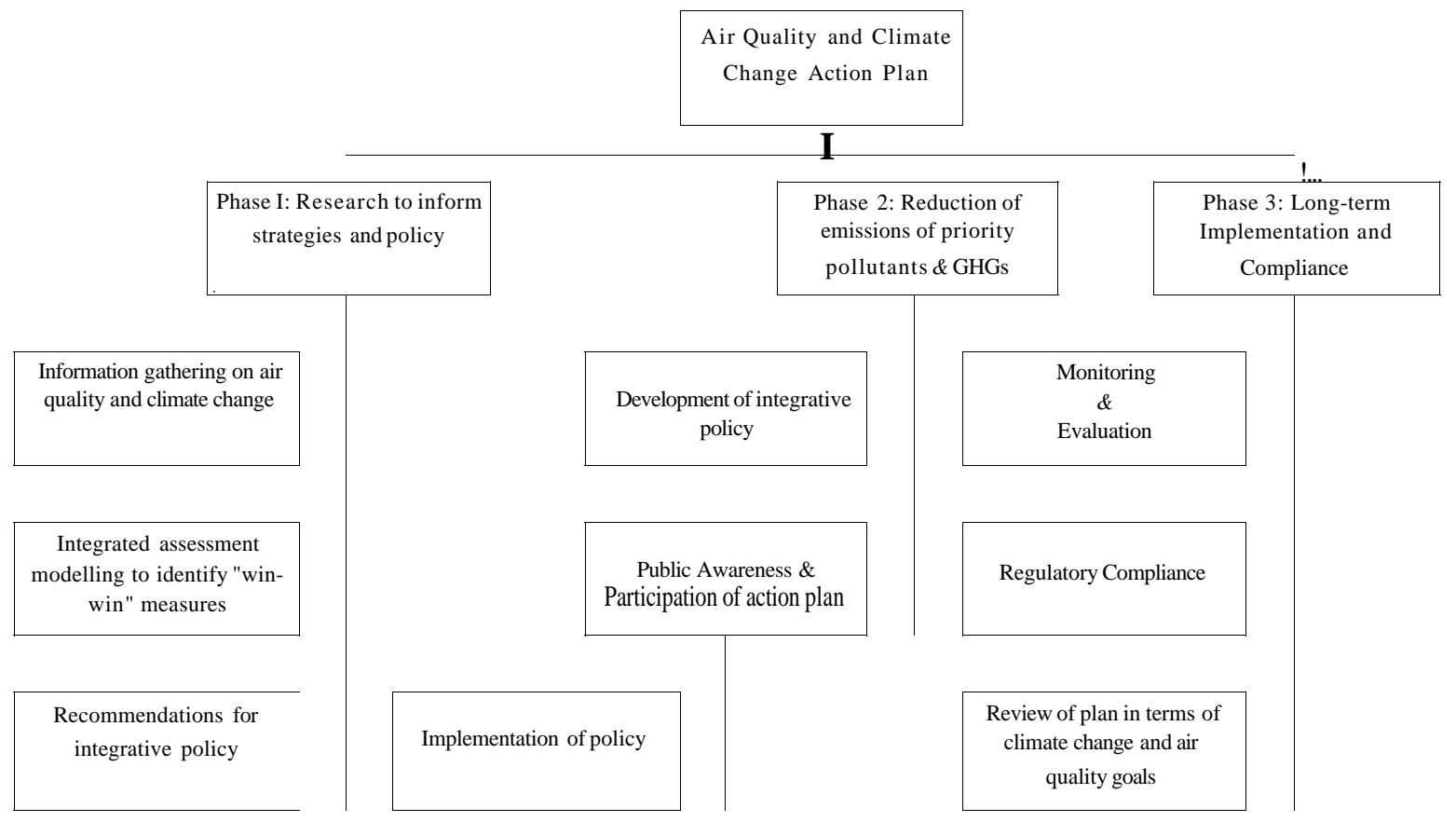
Figure 2: Different phases to be undertaken by municipalities to develop their Air Quality and
Climate Change Action Plans

greenhouse gases in the twenty-first century. Philosophical Transactions of the Royal Society, 365, 1915-1923.

Andreae, M.O. and Crutzen, P.J. (1997). Atmospheric Aerosols: Biogeochemical Sources and Role in Atmospheric Chemistry. Science, 276, 1052-1058.

Bell, M. and Ellis, H. (2004). Sensitivity analysis of tropospheric ozone to modified biogenic emissions for the midatlantic region. Atmospheric Environment, 38, 1879-1889.

Bernard, S.M., Samet, J.M., Grambsch, A., Ebi, EX. and Romieu, I. (2001). The potential impacts of climate variability and change on air pollution -related health effects in the US. Environmental Health Perspectives, 109(2), 199209.

Bestill, M.M. (2001). Mitigating climate change in US cities: opportunities and obstacles. Local Environment, 6(4), 393-406.

Brasseur, G.P., Schultz, M., Granier, C, Saunois, M., Diehl, T., Botzet, M. and Roeckner, E. (2006). Impact of Climate Change on the Future Chemical Composition of the Global Troposphere. Journal of Climate - Special Edition. 19, 39323951.

Boubel, R.W.; Fox, D.L.; Turner, D.B., and Stern, A.C. (1994). Fundamentals of Air Pollution, Third Edition, Academic Press, San Diego.

Clean Air and Climate Protection Software (CACPS), 2007). Clean Air and Climate Protection Software: A joint Project of STAPPA/ALLAPCO, ICELI and the EPA. Available at: http:/ /wwwxacpsoftware.org/ Date accessed: 15 June, 2007.
Dentener, F., Stevenson, D., Ellingsen, K., van Noije, T., Schultz, M., Amann, M., Atherton, C, Bell, N., Bergmann, D., Bey, I., Bouwman, L., Butler, X, Cofala, J., Fiore, A. Gauss, M., Hauglustaine, D., Horowitz, L., Isaksen, I.S.A., Josse, B., Lawrence, M, Krol, M., Lamarque, J.F., Montanaro, V, Muller, J.F., Peuch, V.H., Pitari, G., Pyle, J., Rast, S., Rodriguez, J., Sanderson, M., Savage, N.H., Shindell, D., Strahan, S., Szopa, S., Sudo, K., van Dingenen, R., Wild. O., and Zeng, G. (2006). The Global Atmospheric Environment for the next generation. Environment Science and Technology, 40, 3586-3594.

European Environment Agency (EEA), (2004). Air pollution and climate change policies in Europe: exploring linkages and the added value of an integrated approach. EEA Technical Report. No 5/2004. Available at:http://reports.eea.europa.eu/

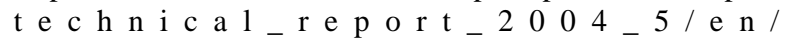
Technical_report_5_2004_web.pdf

Date accessed: 18 June 2007

eThekwini Municipality. (2007). Draft "Air Quality Management Plan for eThekwini Municipality, KwaZulu Natal". Produced by eThekwini Health and the Norwegian Institute for Air Research. Available at: http://www2.nilu.no/AirQuality/data/reports/\{B2D475E8BCDC-BAD1-AF03- 9D183B89D4B5\}.pdf Date accessed: 7 May 2007.

Forster, P., Ramaswamy, V., Artaxp. P., Bersten, T., Betts, R., Fahey, D.W., Haywood, J., Lean, J., Lowe, D.C., Myhre, G., Nganga, J., Prinn, R., Raga, G., Schulz, M. and Van Dorland, R. (2007). Changes in Atmospheric Constituents and in Radiative Forcing. In: Climate Change 2007: The Physical Basis. Contribution of Working Group 1 to the Fourth Assessment Report of the Intergovernmental Panel on climate Change [Solomon, S., Qin, D., Manning, M., Chen, Z., Marquis, M., Averyt, K.B., Tignor, M. and Miller, H.L. (eds)]. 
Cambridge University Press, Cambridge, United Kingdom and New York, NY, USA.

Grewe, V. (2007). Impact of climate variability on tropospheric ozone. Science of Total Environment, 374, 167-181.

Hamilton (2006). Air Quality and Climate Change Corporate Strategic Plan. Available at http://www.myhamilton.ca/NPv/ rdon!yres/C43C2AB2-0F88-4076-A49A92AD9D3429AC/0/ FTNAL_AQCCStratPlanPhase 1 .pdf Date accessed 20 May 2007.

Hong, Y., John, J., Oosthuizen, R., van Tiehoven, M. and Zunckel, M. (2002). Impacts of air pollution in South Africa. Proceedings of "Workshop on Impacts of Air pollution in Southern Africa. Lusaka, Zambia, 27-28 May, 2002.

Hounsome, R. (2007). Urban integrated assessment framework for climate change. Global scenario's and IDP assessment. CSIR, Golder Associates. Report No: CCUIAF-Dur-2-Final, submitted to EThekiwini Municipality. $10 \mathrm{pp}$

Intergovernmental Panel on Climate Change (IPCC) ,2001. Third assessment report of the IPCC. Summary for policymakers a report of Working Group 1 of the Intergovernmental Panel on Climate Change. Available at: http://www.ipcc.ch/ pub/spm22-01.pdf Date accessed: 23 May 2007

Kaufman, Y.J., Fraser, R.S. and Mahoney, R.L. (1990). Fossil fuel and biomass burning effect on climate-heating or cooling? Journal of Climate, 4, 578-588.

Krupnick, A., Burtraw, D. and Markandaya, A. (2002). The ancillary benefits and costs of climate change mitigation: A conception Framework. Available at: http://www.oecd.org/ dataoecd/31/46/2049184.pdf Date accessed 23 May, 2007.

Leung, L. R., and W. I. Gustafson Jr. (2005), Potential regional climate change and implications to U.S. air quality, Geophysical Research Letters, 32, L167 11, doi: 10.1 029/ 2005GL0229 11 .

Matooane, M and Diab, R. (2003). Health Risk Assessment for Sulfur Dioxide Pollution in South Durban, South Africa. Archives of Environmental Health, 58 (12), 763-770.

Mayerhofer, P., de Vries, B., den Elzen, M., van Vuuren, D., Onigkeit, J., Posch, M. and Guardans, R. (2002). Long-term consistent scenarios of emissions, deposition, and climate change in Europe. Environmental Science and Policy, 5,273305.

Meehl, G.A., Zwiers, F., Evans, J., Knutson, X, Mearns, L. and Whetton, P. (2000). Trends in Extreme Weather and Climate Events: Issues Related to Modelling Extremes in Projections of Future Climate Change. Bulletin of the American Meteorological Society, 81(3), 427-436.

Mukheibir, P. (2007). Possible climate change impacts on large hydroelectricity schemes in Southern Africa. Journal of Energy in Southern Africa, 18(1), 4-9.

Mickley, L. J., Jacob, D. J., Field, B. D. and Rind, D. (2004), Effects of future climate change on regional air pollution episodes in the United States, Geophysical Research Letters, 31,L24103,doi: 10.1029/2004GL021216.
Oltmans, S.J., Lefhon, A.S., Harris, J.M., Galbally, I., Scheel, H.E., Bodeker, G., Brunke, E., Claude, H., Tarascick, D., Johnson, B.J., Simmonds, P., Shadwick, D., Anlauf, K., Hayden K., Schmidlin, F., Fujimoto, T., Akagi, K., Meyer, C., Nichol, S., Davies, J., Redondas, A. and Cuevas, E. (2006). Longterm changes in tropospheric ozone. Atmospheric Environment, 40, 3156-3 173 .

Pahl-Wostl, C. (2007). The implications of complexity for integrated resources management. Environmental Modelling \& Software, 22, 56 1-569.

Prather, M., Gauss, M., Berntsen, X, Isaksen, I., Sundet, J., Bey, I., Brasseur, G.,Dentener, F., Derwent, R., Stevenson, D., Grenfell, L., Hauglustaine, D., Horowitz, L., Jacob, D., Mickley, L., Lawrence, M., von Kuhlmann, R., Muller, J-F., Pitari, G., Rogers, H., Johnson, M., Pyle, J., Law, K., van Weele, M. and Wild, O. (2003). Fresh air in the 21 st century? Geophysical Research Letters, 30 (2), 1100, doi: 10.1029/ 2002 GLO16285.

Posch, M., Hettelingh, J-P., Alcamo, J. and Krol, M. (1996). Integrated scenarios of acidification and climate change in Asia and Europe. Global Environmental Change, 6 (4), 375-394.

Racherla, P.N. and Adams, P. J. (2007). The response of surface ozone to climate change over the Eastern United States. Atmospheric Chemistry Physics Discussions, 7, 9867-9897.

Shindell, D., Faluvegi, G., Lacis, A., Hansen, J., Ruedy, R. and Aguilar, E. (2006). Role of tropospheric ozone increases in 20th century climate change. Journal of Geophysical Research, 111,D08302, doi: 10.1029/2005JD006348.

Swart, R., Amann, M., Rues, F. and Tuinstra, W., (2004). A Good Climate for Clean Air: Linkages between Climate Change and Air Pollution. An Editorial Essay. Climatic Change, 66(3): 263-269.

Tao, Z. Williams, A., Donaghy, K. and Hewings, G. 2007) A socio-economic method for estimating future air pollutant emissions-Chicago case study, Atmospheric Environment, In Press. doi:10.1016/j.atmosenv.2007.02.013

West, J.J. and Fiore, A. M. (2005). Management of tropospheric ozone by reducing methane emissions Environmental Science \& Technology, 39 (13) 4685-4691.

Williams, M. and Chiotti, Q. (2006). Emerging Challenges and Opportunities in the Development of Clean Air Policy Strategies. NERAM Guidance Document on Air Quality Risk Management. NERAM V Colloquium Strategic Policy Directions for Air Quality Risk Management (16-18 October, 2006)

Available at: http://www.irr-neram.ca/ Guidance\%20Documents/GD_Chapt_5.pdf Date accessed 28 May 2007

Wuebbles, D.J. and Hayhoe, K. (2002). Atmospheric methane and global change. Earth-Science Reviews, 57, 117-210.

Yienger, J., Bell, R. And Royael, M. (2007). Integrating Climate and Air Emissions Action Planning. Available at: http:/ /www.epa.gov/tm/chief/conference/eil3/ghg/beIl.pdf Date accessed 18 June, 2007 